\title{
COMPARATIVE STUDY OF COMBINED SPINAL AND EPIDURAL AND EPIDURAL ANAESTHESIA IN GYNAECOLOGICAL SURGERIES
}

\author{
K. Chandrasekhar1, D. Vijayakumar Rao 2
}

${ }_{1}^{1}$ Associate Professor, Department of Anaesthesiology, Gitam Institute of Medical Sciences and Research, Visakhapatnam, Andhra Pradesh, India.

${ }^{2}$ Professor, Department of Anaesthesiology, Gitam Institute of Medical Sciences and Research, Visakhapatnam, Andhra Pradesh, India. ABSTRACT

\section{BACKGROUND}

In an attempt to search for ideal regional anaesthetic technique to meet good degree of relaxation ability, to prolong the level and duration, avoiding supplementation with narcotics or general anaesthesia, minimise the total dose and side effects, we tried sequential combined spinal and epidural technique.

This study was done to combine the benefits of spinal and epidural anaesthesia techniques in terms of rapidity of onset, good degree of reliable sensory and motor blockade with lowest possible doses, less side effects and less drug toxicity.

\section{MATERIALS AND METHODS}

Fifty patients between the ages of 20 - 50 years conforming to ASA Class I and II, to undergo gynaecological surgery, duration of surgery lasting around 120 minutes were included in the present study. Patients with neurological disease, anaemia, hypertension, cardiac and respiratory disorders were eliminated from the study.

\section{RESULTS}

Mean onset time for analgesia (3.62 minutes), time for spread of block to T4 level ( 9.36 minutes), better haemodynamic stability, less total drug dose, higher margin of safety, less intraoperative and postoperative side effects when compared to uncombined spinal and epidural anaesthesia.

\section{CONCLUSION}

Combined spinal and epidural technique is valuable and superior alternative to spinal or epidural alone.

\section{KEY WORDS}

CSE, Spinal, Epidural, Haemodynamic Stability, Total Dose.

HOW TO CITE THIS ARTICLE: Chandrasekhar K, Rao DV. Comparative study of combined spinal and epidural and epidural anaesthesia in gynaecological surgeries. J. Evolution Med. Dent. Sci. 2018;7(21):2592-2598, DOI: 10.14260/jemds/2018/584

\section{BACKGROUND}

Sequential technique of combined spinal epidural block, a small dose of local anaesthetic solution for a spinal and the block is extended cephalad with the epidural dose to produce optimal surgical conditions with minimal haemodynamic changes. The epidural block with the catheter was given as per the conventional standard technique.

\section{Aim of the Study \\ To compare the intraoperative effects of Combined Spinal and Epidural anaesthesia with that of Epidural anaesthesia with bupivacaine in gynaecological surgeries of intermediate duration with reference to analgesia, muscle relaxation and haemodynamic effects.}

\section{MATERIALS AND METHODS}

This non-randomised controlled trial was designed to compare the effects of these two techniques with reference to the onset and intensity of the sensory and motor blockade, the haemodynamic stability with the two procedures and the merits and demerits of each technique were studied.

'Financial or Other Competing Interest': None.

Submission 06-04-2018, Peer Review 05-05-2018,

Acceptance 12-05-2018, Published 21-05-2018.

Corresponding Author:

Dr. K. Chandrasekhar,

Associate Professor, Department of Anaesthesiology,

Gitam Institute of Medical Sciences and Research,

Rishikonda, Visakhapatnam, A. P.

E-mail: doctorkota123@gmail.com

DOI: $10.14260 /$ jemds $/ 2018 / 584$

\section{(c) $(\mathbf{F})$}

Fifty patients between the ages of 30 - 50 years ASA Class I and II, posted for gynaecological surgeries were included in the present study. Patients with neurological disease, anaemia, hypertension, cardiac and respiratory disorders were eliminated from the study.

These patients were non-randomly divided into two groups of 25 patients in each was taken for convenience according to the drug used. Routine PAC and the patients were explained and reassured about the procedure and informed consent was obtained.

The patients were divided into two groups, each group consisting of 25 patients.

\section{Group I}

Received combined spinal and epidural anaesthesia using double-needle, separate interspace technique.

- $\quad 1.6 \mathrm{~mL}$ of hyperbaric bupivacaine was used as spinal dose.

- $2 \mathrm{~mL}$ of $0.5 \%$ bupivacaine per every unblocked segment was given the epidural space to achieve block up to T4.

\section{Group II}

Received epidural anaesthesia with $18 \mathrm{G}$ epidural catheter.

- $15 \mathrm{~mL}$ of $0.5 \%$ bupivacaine given as initial bolus dose.

- $2 \mathrm{~mL}$ of $0.5 \%$ bupivacaine per every unblocked segment was given to achieve a T4 block.

\section{Technique}

Preoperatively blood pressure, pulse rate and respiratory rate were recorded. Preload of $10 \mathrm{~mL} / \mathrm{kg}$. Ringer Lactate was given. 
Group I patients receiving combined spinal epidural technique, L 2-3 space was identified and infiltrated with 1\% xylocaine. Epidural space was identified with 18G Tuohy needle by loss of resistance technique and epidural catheter was introduced into the epidural space and the needle was withdrawn. Then, a 25G Quincke's spinal needle is introduced into L3-L4 space and a midline lumbar puncture was performed. $1.6 \mathrm{~mL}$ of heavy bupivacaine was injected into the subarachnoid space. Then the epidural catheter was fixed firmly on to the back of the patient and patient repositioned into supine position. After assessing the onset of sensory and motor block, $3 \mathrm{~mL}$ of $2 \%$ xylocaine with adrenaline was injected through the epidural catheter and patient observed for 5 mins. After satisfying that there were no systemic complication or inadvertent subarachnoid injection, the subsequent dose of $2 \mathrm{~mL} 0.5 \%$ plain bupivacaine per unblocked segment was administered to achieve a block up to T4 through catheter. $1,2,3,4,5$

For the patients receiving epidural anaesthesia, an 18G Tuohy's epidural needle was introduced in the L2-L3 space after local infiltration of the skin with $1 \%$ lignocaine solution. Epidural space was identified by loss of resistance technique. An 18G Portex Epidural catheter was introduced into the epidural space and the needle withdrawn. The catheter was fixed firmly on to the back of the patient and the patient repositioned into supine position $3 \mathrm{~mL}$ of $2 \%$ xylocaine with adrenaline was injected and the patient was observed for 5 mins. After satisfying that there is no systemic complication or inadvertent subarachnoid injection, bolus dose of $15 \mathrm{~mL}$ of $0.5 \%$ bupivacaine was given through catheter. $2 \mathrm{~mL}$ bupivacaine per unblocked segment to achieve block up to T4 level was given through catheter.

Epidural catheter dislodgement was defined as any catheter that functioned well and subsequently ceased to function after administration of additional local anaesthetic. Inadvertent intravascular placement of catheter evidenced by aspiration of blood into catheter, in such case catheter was withdrawn and tried in different space.

Unilateral or incomplete sensory analgesia was defined as any epidural catheter associated with more than two dermatomal sensory disparity or associated with patient discomfort or patchy sensory analgesia, paraesthesia.

\section{Monitoring of Cardiac and Respiratory Parameters}

Pulse rate, blood pressure and respirations were recorded at every 5 mins for the first 20 mins and then onwards for every 10 mins. The time of injection of the local anaesthetic solution into the spinal or the epidural space was noted. After 2 mins the onset of sensory analgesia was detected by testing the response to pin prick and onset of motor block by asking the patient to move the limbs and the time of onset for both was noted in the chart. 6,7

\section{Assessment of Sensory Blockade}

1. Onset of Sensory Paresis: The time interval between the injection and upper limit analgesia. It was determined every 30 secs interval after 2 mins following the injection of drug in the spinal or epidural space until the beginning of surgery. Onset of analgesia was taken as loss of sensation of pinprick with a $26 \mathrm{G}$ needle, but ideally by ice cube.

\section{Level of Sensory Block}

For CSE- Sensory block height was measured 3 mins after subarachnoid injection and then at 2 mins interval until it has stopped rising and the level noted. After administration of epidural dose, the maximum block height noted.

For Epidural- Sensory block height was measured after injection of total dose of drug into the epidural space and the level noted.

\section{Time for Maximum Spread}

The time interval from the injection to the maximum cephalad spread to a level of T4 after the subsequent epidural dose was noted.

\section{Degree of Sensory Block}

Assessment was done using Visual Analogue Scale Score.

\begin{tabular}{|c|r|l|l|c|}
\hline Grade I & \multicolumn{2}{|c|}{0} & - & None \\
\hline Grade II & 0.1 & -2.5 & - & Mild Pain \\
\hline Grade III & 2.6 & -5.0 & - & Moderate Pain \\
\hline Grade IV & 5.1 & -7.5 & - & Severe Pain \\
\hline Grade V & 7.6 & -10 & - & Worst Possible Pain \\
\hline
\end{tabular}

\section{Assessment of Motor Blockade}

1. Onset of Motor Paresis: The time interval between the injection and the inability of the patient to flex her hip and knees. It was evaluated every 5 mins until the beginning of the surgery.

2. Degree of Motor Block: Assessment was done using Bromage Scale.

Grade I

$0 \%$ - No Block - Full flexion of knee and ankle possible.

\section{Grade II}

33\% - Partial Block - Able to flex ankle normally with impaired knee flexion.

\section{Grade III}

$66 \%$ - Almost complete Block - Unable to flex knee, but still able to flex ankle.

\section{Grade IV}

$100 \%$ - Unable to flex knee or ankle.

\section{Total dose of bupivacaine given}

The total dose of bupivacaine required for the surgery in the two techniques, CSE and epidural was noted.

\section{Intraoperative Monitoring}

Pulse rate, blood pressure, oxygen saturation and respiratory rate were monitored continuously. Regular assessment of level of sensory blockade was done after epidural top-up doses. Sedation was provided with IV midazolam. Side effects hypotension, bradycardia, nausea, vomiting and restlessness are treated appropriately.

\section{Postoperative Observations}

The patients were observed constantly in post-operative unit for complications like headache, backache, nausea, vomiting, dizziness, pruritus, bradycardia, hypotension and respiratory depression. Resuscitative measures were kept in hand at all times. 


\section{Statistical Analysis}

The SPSS software version 15 was used to calculate the descriptive statistics for continuous variables such as age, weight, mean and standard deviation. The inferential statistics for hypothesis testing was done using unpaired " $t$ " test. Categorical data were compared using the Chi-square test.

\section{RESULTS}

\section{Group - I}

Received combined spinal epidural anaesthesia using double-needle, separate interspace technique-

- $\quad 1.6 \mathrm{~mL}$ of hyperbaric bupivacaine was used as spinal dose.

- $2 \mathrm{~mL}$ of $0.5 \%$ bupivacaine per every unblocked segment was given through catheter to achieve a T4 block.

\section{Group - II}

Received epidural anaesthesia with 18G Portex epidural catheter-

- $15 \mathrm{~mL}$ of $0.5 \%$ bupivacaine given as initial bolus dose.

- $2 \mathrm{~mL}$ of $0.5 \%$ bupivacaine per every unblocked segment was given to achieve a T4 block.

Demographic Data- Characteristics of Patients

\begin{tabular}{|c|c|c|c|}
\hline & Group I & Group II & P value \\
\hline No. of cases & 25 & 25 & $>0.05$ \\
\hline Age (in years) & $34.96(5.76)$ & $37.04(8.02)$ & $>0.05$ \\
\hline Weight (in kgs) & $50.72(6.16)$ & $51.6(4.61)$ & $>0.05$ \\
\hline Height (in cms) & $155.2(4.0)$ & $154.52(3.4)$ & $>0.05$ \\
\hline \multicolumn{4}{|c|}{ Table 1. Age and Weight and Height } \\
Distribution- Mean (SD) & \\
\hline
\end{tabular}

Table 1 shows distribution of age, height and weight of the patients in both groups and were found to be similar in both the Group II. The mean weight was 50.72 in Group I and 51.60 in Group II. The mean height was 155.20 and 154.20 in Group I and Group II respectively. The differences in the means of demographic data of the patients in the two groups are not statistically significant ( $p$ value $>0.05$ ). $8,9,10,11$

\begin{tabular}{|c|c|c|}
\hline Operation & Group I & Group II \\
\hline $\begin{array}{l}\text { Total Abdominal } \\
\text { Hysterectomy }\end{array}$ & 15 & 21 \\
\hline Vaginal Hysterectomy & 6 & 2 \\
\hline Ward Mayo's & 2 & 1 \\
\hline Laparotomy & 2 & 1 \\
\hline Total & 25 & 25 \\
\hline \multicolumn{3}{|c|}{$\begin{array}{l}\text { Table 2. The different Surgical Procedures carried out in } \\
\text { Each Group }\end{array}$} \\
\hline
\end{tabular}

\section{Characteristics of Sensory Blockade}

\begin{tabular}{|c|c|c|c|}
\hline & Group I & Group II & P value \\
\hline Sensory Blockade (in mins) & $3.52(0.5)$ & $\begin{array}{l}13.92 \\
(1.15)\end{array}$ & $<0.05$ \\
\hline Height of Block (initial dose) & $\begin{array}{c}\mathrm{T} \\
9.04(0.93)\end{array}$ & $\begin{array}{l}\text { T } 6.68 \\
(0.47)\end{array}$ & - \\
\hline $\begin{array}{l}\text { Time to Complete Spread T4 } \\
\text { (in mins) }\end{array}$ & \begin{tabular}{|c|}
9.36 \\
$(0.63)$
\end{tabular} & $\begin{array}{l}17.44 \\
(1.29)\end{array}$ & $<0.05$ \\
\hline
\end{tabular}

Table 4 shows the mean onset time of sensory blockade in Group I to 3.52 mins which is rapid when compared to the latency observed in the mean onset time of 13.92 mins in
Group II occurring at a mean duration. A mean level of T 9.04 under spinal dose and a T4 level was achieved with epidural dose in the combined spinal epidural group, whereas in the epidural group a mean level of T6.68 was achieved with initial bolus which was extended to level of $\mathrm{T} 4$ with top-up dose. The difference in the onset of sensory blockade in the two groups is statistically significant $(p<0.05)$. The mean time for maximum cephalad spread of T4 level was 9.36 mins in Group I and 17.44 mins in Group II and the difference was statistically significant $(\mathrm{p}<0.05)$.

\begin{tabular}{|c|c|c|}
\hline & Group I & Group II \\
\hline ASA Grade I & 17 & 14 \\
\hline ASA Grade II & 8 & 11 \\
\hline Preoperative Pulse Rate & $89.32(8.03)$ & $87.32(5.42)$ \\
\hline Preoperative Sys BP & $121.2(10.13)$ & $123.6(9.94)$ \\
\hline Preoperative Dia BP & $81.84(5.59)$ & $83.6(6.37)$ \\
\hline \multicolumn{3}{|c|}{ Table 4. Preanaesthetic Variables } \\
\hline
\end{tabular}

Table 3 shows the preanaesthetic variables in both the groups.

\begin{tabular}{|c|c|c|c|}
\hline \multirow{2}{*}{ Grade I (0) } & $\begin{array}{c}\text { No. of } \\
\text { patients }\end{array}$ & 25 & 18 \\
\cline { 2 - 4 } & $\%$ & $100 \%$ & $72 \%$ \\
\hline \multirow{2}{*}{$\begin{array}{c}\text { Grade II (0.1- } \\
\text { 2.5) }\end{array}$} & $\begin{array}{c}\text { No. of } \\
\text { patients }\end{array}$ & - & 5 \\
\cline { 2 - 4 } & $\%$ & - & $20 \%$ \\
\hline \multirow{2}{*}{$\begin{array}{c}\text { Grade III (2.6-5) } \\
\text { Go. of } \\
\text { patients }\end{array}$} & - & 2 \\
\cline { 2 - 4 } 7.5) (5.1- & $\begin{array}{c}\text { No. of } \\
\text { patients }\end{array}$ & - & $8 \%$ \\
\cline { 2 - 4 }$\%$ & - & - \\
\hline \multirow{2}{*}{$\begin{array}{c}\text { Grade V (7.6-10) } \\
\text { patients }\end{array}$} & - of & - \\
\cline { 2 - 4 } & $\%$ & - & - \\
\hline \multicolumn{2}{|c|}{ Table 5. Intensity of Sensory Blockade (VAS Score) } \\
\hline
\end{tabular}

Table 5 shows that intensity of sensory blockade in Group I is of Grade I in $100 \%$ cases, whereas intensity of sensory blockade in Group II is of Grade I in only $72 \%$ of cases. Grade II intensity of pain was observed in $20 \%$ cases and Grade III in $8 \%$ of cases in Group II patients. Thus, Visual Analogue Scale Score was more in Group II when compared to Group I. Thus, in Group I all the 25 patients had a VAS score of 0, i.e. perceived no pain whereas in Group II 5 of the 25 patients perceived mild pain with a VAS score in the range of 0.1-2.5 and 2 patients complained of moderate pain in the range of 2.6-5 VAS score. ${ }^{12,13}$

\section{Characteristics of Motor Blockade}

\begin{tabular}{|c|c|c|c|}
\hline & Group I & Group II & P value \\
\hline $\begin{array}{c}\text { Motor Blockade (in } \\
\text { minutes) }\end{array}$ & $5.6(0.57)$ & $20.36(2.25)$ & $<0.05$ \\
\hline \multicolumn{2}{|c|}{ Table 6. Onset of Motor Block-Mean (SD) } \\
\hline
\end{tabular}

Table 6 shows that mean onset time of motor blockade in Group I is 5.6 mins, which is earlier when compared to Group II where the onset was delayed occurring at 20.36 mins. The difference in onset of motor blockade in two groups is statistically significant $(\mathrm{p}<0.05)$. 


\begin{tabular}{|c|c|c|c|}
\hline & & Group I & Group II \\
\hline \multirow[t]{2}{*}{ Grade 0} & No. of patients & - & - \\
\hline & $\%$ & - & - \\
\hline \multirow[t]{2}{*}{ Grade I } & No. of patients & - & - \\
\hline & $\%$ & - & - \\
\hline \multirow[t]{2}{*}{ Grade II } & No. of patients & - & 20 \\
\hline & $\%$ & - & $80 \%$ \\
\hline \multirow[t]{2}{*}{ Grade III } & No. of patients & 25 & 5 \\
\hline & $\%$ & $100 \%$ & $20 \%$ \\
\hline
\end{tabular}

Table shows that in Group I the intensity of motor blockade was of Grade III in $100 \%$ cases when compared to Group II where only $20 \%$ of cases had motor blockade of Grade III and $80 \%$ of patients had motor blockade of Grade II.

\section{Haemodynamic Changes}

\begin{tabular}{|c|c|c|c|}
\hline Time Interval & Group I & Group II & P value \\
\hline Preoperative & $89.32(8.03)$ & $87.32(5.42)$ & $>0.05$ \\
\hline 5 mins & $86.08(8.95)$ & $84.96(5.83)$ & $>0.05$ \\
\hline 15 mins & $82.56(9.30)$ & $84.24(6.56)$ & $>0.05$ \\
\hline 30 mins & $80.0(7.85)$ & $80.72(8.2)$ & $>0.05$ \\
\hline $60 \mathrm{mins}$ & $81.84(6.24)$ & $81.44(6.06)$ & $>0.05$ \\
\hline $90 \mathrm{mins}$ & $82.28(6.41)$ & $84.4(5.5)$ & $>0.05$ \\
\hline 120 mins & $84.24(6.0)$ & $86.32(5.61)$ & $>0.05$ \\
\hline \multicolumn{4}{|c|}{ Iable 8. Changes in the Heart Rate (in minutes) at Various } \\
\hline
\end{tabular}

\begin{tabular}{|c|c|c|}
\hline Preoperative & $\mathbf{0}$ & $\mathbf{0}$ \\
\hline $5 \mathrm{mins}$ & -3.24 & -2.36 \\
\hline $15 \mathrm{mins}$ & -6.76 & -3.0 \\
\hline $30 \mathrm{mins}$ & -9.32 & -6.6 \\
\hline $60 \mathrm{mins}$ & -6.68 & -5.48 \\
\hline $90 \mathrm{mins}$ & -7.04 & -3.0 \\
\hline $120 \mathrm{mins}$ & -5.08 & -1.24 \\
\hline \multicolumn{2}{|c|}{ Table 9. Changes in Pulse Rate from Baseline } \\
\hline
\end{tabular}

Table 8 and 9 show that there was a fall in the pulse rate with the maximum reduction seen in the first 30 minutes in both the groups, after which the pulse rate was seen to return to below baseline values. The difference in the degree of fall in the pulse rate in both the groups is statistically insignificant ( $p>0.05)$.

\begin{tabular}{|c|c|c|c|}
\hline Time Interval & Group I & Group II & P value \\
\hline Preoperative & $112.910 .13)$ & $123.6(9.94)$ & $>0.05$ \\
\hline 5 mins & $110.64(10.06)$ & $117.6(8.86)$ & $>0.05$ \\
\hline 15 mins & $104.24(9.13)$ & $108.64(7.2)$ & $>0.05$ \\
\hline 30 mins & $98.64(6.42)$ & $106.48(7.46)$ & $>0.05$ \\
\hline 60 mins & $100.64(7.49)$ & $101.12(8.96)$ & $>0.05$ \\
\hline 90 mins & $107.68(6.23)$ & $1.9 .76(4.66)$ & $>0.05$ \\
\hline 120 mins & $113.696 .32)$ & $115.76(5.86)$ & $>0.05$ \\
\hline $\begin{array}{r}\text { Table 10. Changes in Systolic Blood Pressure (mmHg) at } \\
\text { various Time Intervals Mean (SD) }\end{array}$ \\
\hline \multicolumn{4}{|c}{} \\
\hline
\end{tabular}

\begin{tabular}{|c|c|c|}
\hline Preoperative & $\mathbf{0}$ & $\mathbf{0}$ \\
\hline 5 mins & $-10.16(5.47)$ & $-6.8(5.38)$ \\
\hline $15 \mathrm{mins}$ & $-17.12(7.07)$ & $-14.9(8.5)$ \\
\hline $30 \mathrm{mins}$ & $-22.56(9.15)$ & $-17.44(6.25)$ \\
\hline $60 \mathrm{mins}$ & $-20.56(10.02)$ & $-20.08(11.06)$ \\
\hline $90 \mathrm{mins}$ & $-13.52(7.12)$ & $-14.24(6.93)$ \\
\hline 120 mins & $-7.92(5.36)$ & $-7.84(5.71)$ \\
\hline \multicolumn{3}{|c|}{ Table 11. Changes in Systolic Pressure (mmH) from the } \\
Baseline \\
\hline
\end{tabular}

Table 10 and 11 shows that there was a gradual fall in the systolic blood pressures in both the groups. The degree of fall in systolic blood pressure mean value was more in Group I than in Group II, but the difference in fall was not statistically significant except at 30 mins interval where the difference in fall was statistically significant $(p<0.05)$. In Group I the maximum fall was observed at 30 mins interval, whereas in Group II it was seen at 60 minutes interval after which the pressures have slowly returned to below baseline values. ${ }^{14}$

\begin{tabular}{|c|c|c|c|}
\hline Time Interval & Group I & Group II & P value \\
\hline Preoperative & 81.84 (5.59) & $83.6(6.37)$ & $>0.05$ \\
\hline 5 mins & $77.04(6.0)$ & $80.48(6.11)$ & $>0.05$ \\
\hline 15 mins & $73.6(5.22)$ & $76.16(5.74)$ & $>0.05$ \\
\hline 30 mins & 71.76 (4.17) & $72.48(5.72)$ & $>0.05$ \\
\hline 60 mins & $72.8(4.35)$ & $73.44(4.45)$ & $>0.05$ \\
\hline 90 mins & $76.16(3.91)$ & $76.72(4.31)$ & $>0.05$ \\
\hline 120 mins & $78.72(2.93)$ & $79.28(4.72)$ & $>0.05$ \\
\hline \multicolumn{4}{|c|}{$\begin{array}{c}\text { Table 12. Changes in Diastolic Blood Pressure (mmHg) at } \\
\text { various Time Intervals Mean (SD) }\end{array}$} \\
\hline
\end{tabular}

\begin{tabular}{|c|c|c|c|}
\hline Time Interval & Group I & Group II & P value \\
\hline Preoperative & $94.64(6.0)$ & $96.64(6.79)$ & $>0.05$ \\
\hline 5 mins & $88.0(6.39)$ & $92.52(6.02)$ & $>0.05$ \\
\hline 15 mins & $83.64(5.83)$ & $86.68(5.11)$ & $>0.05$ \\
\hline 30 mins & $80.24(4.24)$ & $83.6(5.5)$ & $>0.05$ \\
\hline 60 mins & $81.8(4.89)$ & $82.2(5.6)$ & $>0.05$ \\
\hline 90 mins & $85.90(4.23)$ & $87.24(4.07)$ & $>0.05$ \\
\hline 120 mins & $89.92(3.49)$ & $91.2(4.64)$ & $>0.05$ \\
\hline Table 13. Changes in Mean Arterial Pressure (mmHg) at \\
various Time Intervals Mean (SD) \\
\hline
\end{tabular}

Table 12 and 13 shows that the fall in diastolic and mean arterial pressures were more in Group I than in Group II patients, but the difference in the fall was statistically insignificant. It was thus observed that combined spinal epidural group of patients had a comparable haemodynamic stability to that of the more stable epidural group of patients.

\section{Cardiorespiratory Changes}

\begin{tabular}{|c|c|c|c|}
\hline $\begin{array}{c}\text { Mean decrease in } \\
\text { systolic pressure }\end{array}$ & $-15.3(5.79)$ & $-13.30(5.25)$ & $>0.05$ \\
\hline $\begin{array}{c}\text { Mean decrease in } \\
\text { heart rate }\end{array}$ & $-6.35(2.40)$ & $-3.61(2.01)$ & $>0.05$ \\
\hline $\begin{array}{c}\text { Mean decrease in } \\
\text { respiratory rate }\end{array}$ & $-0.01(0.03)$ & $-0.1(0.1)$ & $>0.05$ \\
\hline $\begin{array}{c}\text { Mean decrease in } \\
\text { oxygen saturation }\end{array}$ & Nil & Nil & $>0.05$ \\
\hline
\end{tabular}

Table 14. Haemodynamic and Respiratory Effects-Mean (SD)

Table 14 shows the mean decrease in the systolic blood pressure from the preoperative value in Group I was 15.3 and from Group II was 13.3, but the difference in decrease of systolic blood pressure between the two groups was not statistically significant. The mean decrease in the heart rate from the preoperative value was 6.35 in Group I and that for Group II was 3.61. The mean decrease in respiratory frequency from preoperative value in Group I and Group II were 0.03 and 0.1 breaths/ min respectively. The oxygen saturation was found to be always above $95 \%$ in both the groups. The above values in both the groups were statistically not significant with a p-value $>0.05$. 


\begin{tabular}{|c|c|c|c|}
\hline & Group I & Group II & P value \\
\hline $\begin{array}{c}\text { Total dose of } \\
\text { bupivacaine (mg) }\end{array}$ & $\begin{array}{c}62.8 \\
(11.9)\end{array}$ & $\begin{array}{c}117.2 \\
(8.04)\end{array}$ & $>0.05$ \\
\hline
\end{tabular}

Table 15 shows that the total requirements of bupivacaine to maintain optimal surgical conditions throughout the procedure in Group I was $62.8 \mathrm{mg}$, while in Group II it was $117.0 \mathrm{mg}$. Thus, the total dose of bupivacaine for a T4 block was almost twice the amount in patients receiving epidural block in comparison to combined spinal epidural group.

\section{Complications}

\begin{tabular}{|c|c|c|c|}
\hline 5 & & Group I & Group II \\
\hline 1 & $\begin{array}{l}\text { Catheter related } \\
\text { complications: }\end{array}$ & & \\
\hline (a) & Difficulty in insertion & None & None \\
\hline (b) & Intravenous cannulation & None & None \\
\hline (c) & Blocking of catheter & None & None \\
\hline (d) & Dislodgement of catheter & None & None \\
\hline (e) & Migration of catheter & None & None \\
\hline (f) & $\begin{array}{c}\text { Incomplete/ unilateral } \\
\text { analgesia }\end{array}$ & None & None \\
\hline 2 & Bradycardia & $2(8 \%)$ & $1(4 \%)$ \\
\hline 3 & Hypotension & $7(28 \%)$ & $4(16 \%)$ \\
\hline 4 & Nausea/Vomiting & $3(12 \%)$ & $1(4 \%)$ \\
\hline 5 & Shivering & $1(4 \%)$ & - \\
\hline
\end{tabular}

Table shows that there were no catheter related problems in either of the groups. The incidence of bradycardia in Group I was $8 \%$ and in Group II was 4\%. Hypotension was observed in $28 \%$ of cases in Group I as compared to $4 \%$ in Group II. Shivering was observed in $4 \%$ of patients in Group I, while none was seen in Group II.

\begin{tabular}{|c|c|c|c|}
\hline Sl. No. & & Group I & Group II \\
\hline 1 & Nausea & $2(8 \%)$ & $2(8 \%)$ \\
\hline 2 & Vomiting & None & None \\
\hline 3 & Dizziness & None & None \\
\hline 4 & Pruritus & None & None \\
\hline 5 & Respiratory depression & None & None \\
\hline 6 & PDPH & None & None \\
\hline 7 & Backache & None & None \\
\hline 8 & $\begin{array}{c}\text { Neurological } \\
\text { complications }\end{array}$ & None & None \\
\hline \multicolumn{3}{|c|}{ Table 17. Incidence of Postoperative Complications } \\
\hline
\end{tabular}

Table 17 shows that only nausea was observed post operatively in 8\% of case in both Group I and Group II. No other complications were observed.

\section{DISCUSSION}

Spinal and epidural anaesthesia are the major regional anaesthetic techniques used for lower abdominal surgeries. Major disadvantages of spinal anaesthesia are the inability to extend the block when required and the risk of sudden onset of hypotension and bradycardia with conventional dose. 15

Over the years the introduction of continuous epidural technique has become popular as the block can be extended into the post-operative period, but due to the requirement of large amounts of local anaesthetic to achieve satisfactory sensory and motor block for abdominal surgeries, there is always a risk of toxic complications. Also, in spite of these large doses the epidural block may fail to provide adequate analgesia, relaxation in up to $25 \%$ of patients due to difficulty in the blocking of sacral roots.

Combined spinal epidural anaesthesia is gaining wide popularity, because it combines the versatility of the spinal with the variability of the epidural anaesthesia. Spinal application of local anaesthetic solution achieves a fast response, reliable sensory and motor block at low doses with little toxicity. ${ }^{1}$ Further the block can be maintained or prolonged by intermittent injection of local anaesthetic by the epidural route and postoperative pain relief is possible. The present study was planned to compare the onset and intensity of sensory and motor blockade, the haemodynamic effects, the total dose requirements, the complications and the benefits of using combined spinal epidural anaesthesia with that of continuous epidural anaesthesia.

In our study, the mean time for onset of sensory analgesia with the spinal dose in combined spinal epidural group of patients was 3.62 mins, which achieved a mean level of T9.36 and time to complete spread to T4 after the epidural dose was 9.36 mins. This was significantly rapid than the epidural group where the mean time for onset of action was 13.92 mins with the mean level of T6.68 and the time for complete spread (T4) was 17.44 mins and the difference was statistically significant ( $p$ value $<0.05$ ). Patel $M$ et al (1993) reported the onset time to analgesia at level of T4 in parturients given combined spinal epidural block was on average 7.7 mins. McGlade et al (1997) in a study involving patients receiving $20 \mathrm{~mL}$ of $0.5 \%$ bupivacaine epidural recorded the onset time of analgesia of $10 \mathrm{mins}$ (range of 6 - 15 mins) with max height of block being T6 (C6T10).

A cephalad rise of sensory level of the block under the influence of epidural top-up was noted in our study. A mean level of T9.36 (0.63) under the spinal block and a mean level of T4 after the epidural top-up was achieved in our study. Blumgart et al (1992) in his study concluded that the volume of epidural dose caused the increase in level of blockade. 5 Stienstra et al (1996) reported that not only the volume but the local anaesthetic dose by themselves contribute to increase in dermatomal level of block in combined spinal epidural group. 15

In the present study we observed that in Group I the combined spinal epidural group, the intensity of sensory block was of Grade I. No pain was felt in $100 \%$ of the cases, whereas in Group II the epidural group the intensity of sensory blockade was of Grade I in only $72 \%$ of cases. Rest of the $28 \%$ of patients experienced mild-to-moderate pain (a VAS score ranging between 0.1 and 5), i.e. of Grade II to Grade III. Rawal N et al (1998) reported that all patients receiving combined spinal epidural group had good-toexcellent analgesia, while only $74 \%$ of patients receiving epidural block had similar good pain relief. ${ }^{1}$

In our study, we observed that $28 \%$ of cases in the epidural group needed supplementary narcotic analgesic medication for intraoperative pain and restlessness and there was no need for any supplementary analgesic medication in patients of combined spinal epidural group. Holmstrom B et al (1993) reported that perioperative sedatives and concomitant analgesics were required more 
frequently and in larger doses by patients undergoing surgery with epidural block $(\mathrm{p}<0.05)$ than with combined spinal epidural or spinal block alone.

The onset of motor blockade was significantly early in combined spinal epidural group being 5.6 mins when compared to 20.36 mins in the epidural group. The intensity of motor block was of Grade III (Bromage) in 100\% of cases in Group I, while in Group II only 20\% of patients were observed to have complete motor blockade. In the remaining $80 \%$ of the patients in the epidural group the intensity of motor blockade was of Grade II. Thus, the quality of motor blockade in combined spinal epidural group was more dense and even the surgeon's perception for muscle relaxation was in favour of combined spinal epidural group than the epidural group. Verma UC (1999) reported that onset of motor blockade was rapid 5.5 (5.31) mins and of Grade III type (Bromage) in combined spinal epidural group as compared to epidural group where the onset time was 21.00 (4.89) mins and of Grade I and II.

In our study the total mean dose of bupivacaine required to maintain optimal surgical conditions during the entire procedure was $62.8 \mathrm{mg}$ in combined spinal epidural group, which was smaller as compared to $117.2 \mathrm{mg}$ required in epidural group. The difference was statistically significant $(p<0.05)$. By using combined spinal epidural technique, we can prevent bolus loading with bupivacaine and prevent the risk of toxic plasma levels. Small intermittent dosing of bupivacaine would be safer, may be due to the fact that very slow rise in plasma concentrations are better tolerated than a sudden rise. Rawal N et al (1998) observed that the total dose of bupivacaine for a T4 block was three times larger in patients receiving only epidural block when compared to combined spinal epidural block. Verma UC (1999) reported that total amount of bupivacaine required to attain the same target level was three times in epidural group than for CSE group $(113.3+/-11.78) .{ }^{1}$

In our study there was a gradual fall in the pulse rate in the first 30 mins in both the groups, which returned to below baseline levels by the end of surgery. This difference in fall was statistically insignificant ( $p>0.05$ ). It was observed that the maximum reductions in the systolic $(11 \%)$, diastolic and mean arterial pressure occurred at the 30 mins interval (i.e. 20 mins after the epidural top-up dose) in the combined spinal epidural group. These findings confirmed the extension of block established through the spinal dose by the subsequent epidural top-up. In the epidural group the maximum degree of fall in systolic, diastolic and mean arterial pressure occurred at the 60 mins interval. These findings confirm the delayed onset of fall in pressures occurring with bupivacaine. The fall in combined spinal epidural group was more than that was seen in epidural group, but the difference was statistically insignificant ( $p$ value $>0.05$ ). This shows that both the techniques have comparable haemodynamic stability. Rawal et al (1998) reported a fall of 33\%, whereas Thoren et al (1994) reported a fall of $60 \%$ during conventional combined spinal epidural block. Thus, sequential technique of combined spinal epidural block provides better haemodynamic stability than the conventional technique. ${ }^{4}$

In our study, there were no complications related to the insertion of epidural catheters. There was no incidence of intravascular catheter placement, catheter blockade or dislodgement or migration of catheter into the subarachnoid space, incomplete or unilateral analgesia in either of the groups. The complications observed peroperatively were bradycardia, hypotension, nausea and vomiting and shivering.

The incidence of bradycardia in Group I combined spinal epidural group was $8 \%$ and in Group II it was 4\%. In our study $28 \%$ of patients in combined spinal epidural group developed hypotension, whereas $16 \%$ of patients in the epidural group developed hypotension, though in either group the fall in blood pressure was never alarming and was managed by crystalloids and incremental dose of vasopressor.

Nausea and vomiting were observed in $12 \%$ of patients in Group I and in $4 \%$ of patients in Group II. Shivering was observed in $4 \%$ of patients in combined spinal epidural group

Intraoperatively, the complications occurring in combined spinal epidural group were more when compared to epidural group, but the difference was statistically insignificant ( $p$ value $>0.05$ ).

No incidence of postdural puncture headache was observed with combined spinal epidural group. Backache was not observed in combined spinal epidural group or the epidural group. No neurological complications or sequelae were observed in both the groups. Paraesthesia and neurological sequelae were not observed with Quincke type needles.

In conclusion, combined spinal epidural anaesthesia can be considered as a superior alternative to the conventional epidural anaesthesia. It offers a fast and profound sensory and motor blockade, produces an effective and reliable block with lower doses of local anaesthetic with a comparable haemodynamic stability to that seen with epidural block.

\section{CONCLUSION}

In the present study, the intraoperative effects of combined spinal epidural anaesthesia were compared to that of conventional epidural anaesthesia.

In this study, 50 patients of Class I and Class II undergoing elective gynaecological surgical procedures lasting around 120 minutes were classified into two groups.

Group I received the combined spinal epidural block with $1.6 \mathrm{~mL}$ of hyperbaric bupivacaine $(8 \mathrm{mg}$ ) as the spinal dose followed by $2 \mathrm{~mL}$ of $0.5 \%$ bupivacaine per every unblocked segment as the epidural dose to achieve a block of T4.

Group II received the Epidural block with $15 \mathrm{~mL}$ of $0.5 \%$ bupivacaine as bolus followed by $2 \mathrm{~mL}$ of $0.5 \%$ bupivacaine per every unblocked segment to achieve a block of T4.

The results were studied and compared in the two groups. In this study, we found that the time for onset of analgesia and for the complete spread were rapid in the combined spinal epidural group of patients with the quality of sensory block being more intense in Group I. Also, it was seen that the onset of complete motor blockade was rapid and was associated with a more dense motor block in Group I.

In comparison, in the epidural Group II patients, much latency was observed in the onset and spread of analgesia and motor blockade. The intensity of sensory block was of lesser quality, which led to the requirement of 
supplementary narcotic analgesics in this group of patients. Also, the degree of motor blockade required for lower abdominal surgeries was of lesser grade as sacral roots are not blocked.

Thus, time taken to achieve an effective and reliable block for producing optimal surgical conditions was very less in combined spinal epidural block as compared to epidural block, where much more time was required to provide acceptable surgical conditions.

In this study, it was seen that the total requirement of the drug bupivacaine in the combined spinal epidural group was nearly half of that required for the epidural block. ${ }^{1}$ Therefore, the margin of safety is higher with technique of combined spinal epidural anaesthesia.

Haemodynamic stability was comparable in both the group of patients which also accounts for the low incidence of intraoperative complications seen in both groups of patients.

In conclusion, combined spinal epidural anaesthesia is a new regional technique which combines the benefits of both spinal and epidural approach. This technique achieves a fast response, reliable sensory and motor block at low doses with little toxicity. It is thus a valuable alternative to the established regional anaesthetic techniques.

\section{REFERENCES}

[1] Rawal N, Schollin J, Wesstrom G. Epidural versus combined spinal epidural block for cesarean section. Acta Anaesthesiol Scand 1988;32(1):61-6.

[2] Wakamatsu M, Katoh H, Kondo U, et al. Combined spinal epidural anaesthesia for orthopaedic surgery in the elderly. Masui 1991;40(12):1766-9.

[3] Lyons G, MacDonald R, Mikl B. Combined epidural/ spinal anaesthesia for caesarean section. Through the needle or in separate spaces? Anaesthesia 1992;47(3):199-201.
[4] Guedj P, Eldor J, Gozal Y. Comparative study of conventional spinal anaesthesia and combined spinalepidural anaesthesia in gynaecological surgery. Ann Fr Anaesth Reanim 1992;11(4):399-404.

[5] Blumgart CH, Ryall D, Dennison B, et al. Mechanism of extension of spinal anaesthesia by extradural injection of local anaesthetic. BJA 1992;69(5):457-60.

[6] Shima T, Haga S, Momose K, et al. Combined spinal and epidural analgesia for caesarean section. Masui 1993;42(7):979-84.

[7] Mardirosoff C, Dumont L, Lemedioni P, et al. Sensory block extension during combined spinal and epidural. Reg Anesth Pain Med 1998;23(1):92-5.

[8] Eldor J, Guedj P, Cotev S. Combined spinal epidural anaesthesia. Harefuah 1991;120(4):193-4.

[9] Carrie LE. Extradural, spinal or combined block for obstetric surgical anaesthesia. $\mathrm{Br} \mathrm{J}$ Anaesth 1990;65(2):225-33.

[10] Morris GN, Kinsella M, Thomas TA. Pencil point needles and CSE block. Why needle through needle? Anaesthesia 1998;53(11):1132.

[11] Collier CB, Turner MA. Are pencil point needles safe for subarachnoid block? Anaesthesia 1998;53(4):4112.

[12] Olufolabi AJ, Booth JV. Advantages of combined spinal epidural technique (CSE) technique. Anaesthesia 1999;54(4):396-7.

[13] Bromage PR. Safety and technique with pencil point subarachnoid needles. Anaesthesia 1999;54(4):397.

[14] Leighton BL, Arkoosh VA, Huffnagle S, et al. The dermatomal spread of epidural bupivacaine with or without prior intrathecal sufentanil. Anaes Analg 1996;83(3):526-9.

[15] Trautman WJ, Liu SS, Kopacz DJ. Comparison of lidocaine and saline for epidural top up during combined spinal-epidural anaesthesia in volunteers. Anaes Analg 1997;84(3):574-7. 